\title{
KINETIC AND EQUILIBRIUM STUDIES ON THE REMOVAL OF Pb (II) FROM AQUEOUS SOLUTION USING NETTLE ASH
}

\author{
H. ZAVVAR MOUSAVI* AND S. R. SEYEDI \\ *Department of Chemistry, College of Science, Semnan University, Semnan, Iran \\ (Received: May 27, 2009 - Accepted: July 26, 2010)
}

\begin{abstract}
In this study the removal of $\mathrm{Pb}$ (II) from aqueous solution onto nettle ash (NA) as a low cost adsorbent was reported. Batch mode experiments were conducted at $25{ }^{\circ} \mathrm{C}$ to study the effects of initial concentration of lead ions, contact time, $\mathrm{pH}$ and adsorbent dose on the removal process. It is observed that the adsorption increased with increasing contact time, and the equilibrium was attained after shaking for $30 \mathrm{~min}$. Batch equilibrium experiments exhibited that a maximum lead uptake was obtained at $\mathrm{pH}$ 6.0. The experimental data were analyzed by the Langmuir, Freundlich and Tempkin models and the isotherm data fitted well to the Langmuir isotherm with monolayer adsorption capacity of $1000 \mathrm{mg} / \mathrm{g}$. The cost of removal is expected to be quite low, as the adsorbent is cheap and easily available in large quantities. The present study showed that nettle ash was capable to remove lead ions from industrial wastewater samples.
\end{abstract}

\section{INTRODUCTION}

Contamination of water by toxic heavy metals through the discharge of industrial wastewater is a world wide environmental problem. Heavy metal toxicity can result in damage or reduced mental and central nervous function, lower energy levels and damage to the other vital organs. Lead is an important pollutant introduced into natural waters. The presence of lead in wastewater is dangerous to aquatic flora and fauna even in relatively low concentration and stringent environmental regulation attracts the attention of chemists and environmental engineers for its control. The major sources containing lead are the wastewater from process industries engaged in lead acid battery, paints, oils, mental phosphate, fertilizer, electronic wood production and also combustion of fossil fuel, forest fires, mining activity, automobile emission, sewage waste water, sea spray, etc. are just few examples. ${ }^{1-4}$

Removal of heavy metals is an important problem especially in industrial effluents. Heavy metals are not biodegradable and tend to accumulate in biological systems, posing health hazards if their concentrations exceed allowable limits. ${ }^{5,6}$ Various treatment technologies have been developed for the removal of heavy metals from water and wastewater. The commonly used technologies for removing metal ions from effluents include chemical precipitation, lime coagulation, ion exchange, solvent extraction and adsorption using activated carbon, electrode position and membrane process. ${ }^{7-12}$

In recent years, the discharge of heavy metals into the environment has decreased in many countries due to more stringent legislations, improved cleaning technologies, and altered industrial activities. However, the demand for an economic and environmental friendly method for heavy metals removal still exists. Adsorption ${ }^{13-15}$ is an attractive process, in view of its efficiency and the ease with which it can apply to the treatment of wastewater containing heavy metals. Over last few decades adsorption has gained importance as an effective purification and separation technique used in wastewater treatment. The economics of this process depends mainly on the cost of the adsorbent materials. Although commercial activated carbon, with high surface area, micro porous character and high adsorption capacity, has made its potential adsorbent for the removal of heavy metals from industrial wastewater, it is expensive, has relatively high operation costs. Thus, low cost adsorbents are becoming the focus of many investigations on the removal of heavy metals from aqueous solutions. In recent years, A wide variety of materials such as chitosan [16] granular red mud [17], sugar beet pulp [18], Lignite[19] rice husk [20-22], Zeolite [23], saw-dust [24, 25], leaves[26] and nut walnut shells [27] and eucalyptus camaldulenis tree leaves [28] are examples of low-cost materials used in the removal of heavy metal ions from aqueous solution.

This paper describes a study of the use of nettle ash (NA) as an adsorbent for removal of $\mathrm{Pb}$ (II) from aqueous solutions. The influence of several operating parameters for adsorption of $\mathrm{Pb}$ (II), such as contact time, initial concentration, $\mathrm{pH}$, particle size, adsorbent dose and efficiency of the adsorbent in the removal of Lead (II) in different experimental conditions were investigated in batch mode. In order to understand the adsorption process by nettle ash the kinetics of adsorption has been studied. The equilibrium adsorption characteristics have been modeled using Langmuir, Freundlich and Tempkin isotherms. These studies may be useful for industrial wastewater treatment.

\section{MATERIALS AND METHODS}

All the chemicals used in this study were of analytic grade. The stock solution of $\mathrm{Pb}^{2+}$ was prepared by dissolving $\mathrm{Pb}\left(\mathrm{NO}_{3}\right)_{2}$ in deionized water. A series of $\mathrm{Pb}^{2+}$ solutions used in these experiments were made by diluting the stock solution to the desired concentrations ranging from 20 to $2000 \mathrm{mg} \mathrm{L}^{-1}$. Before mixing these solutions with the adsorbent, $\mathrm{pH}$ values of them were adjusted by adding $0.1 \mathrm{~mol} \mathrm{~L}^{-1} \mathrm{NaOH}$ and $0.1 \mathrm{~mol} \mathrm{~L}^{-1} \mathrm{HNO}_{3}$. E-632 $\mathrm{pH}$ meter (Metrohm) was used to measure the $\mathrm{pH}$ values of the solutions. The concentrations of $\mathrm{Pb}^{2+}$ were determined by atomic absorption spectrometer (AAS; model AA680, Shimadzu), and average values of three replicates were taken for each determination. The surface morphology of the adsorbents was characterized by SEM (Philips PW3710).

\section{Adsorbent preparation}

Nettle is found mostly in northern cities of Iran. This plant is bothersome for farmers and stop process of growth or development of plants and tress, so it should be emitted from this area. Numerous analyses of nettle have revealed the presence of more than fifty different chemical constituents. The roots of stinging nettle have been studied extensively and found to contain starch, gum, albumen, sugar, and two resins. Histamine, acetylcholine, choline, and serotonin are also present. Chemical composition of nettle ash: $\mathrm{Fe}_{2} \mathrm{O}_{3}(1.25 \%)$, $\mathrm{SiO}_{2}(64.70 \%), \mathrm{Al}_{2} \mathrm{O}_{3}(5.30 \%), \mathrm{CaO}(1.64 \%), \mathrm{MgO}(2.1 \%)$ and L.O.I $20.86 \%$. In this study nettle ash was used as an adsorbent for the removal of lead (II) in aqueous solution. Nettle ash was prepared by burning the dried plant materials. A $500 \mathrm{mg}$ of the dried materials taken in a porcelain crucible was burnt at 500 ${ }^{\circ} \mathrm{C}$ in a muffle furnace for $4 \mathrm{~h}$.

\section{Batch adsorption studies}

Batch experiments were carried out at various $\mathrm{pH}(2-8)$, adsorbent dose $\left(1-5 \mathrm{~g} \mathrm{~L}^{-1}\right)$ and stirring speed $(180 \mathrm{rpm})$ for a contact time of $30 \mathrm{~min}$. For each batch experiment, $100 \mathrm{ml} \mathrm{Pb}^{2+}$ solution of $100 \mathrm{mg} \mathrm{L}^{-1}$ concentration was used. After setting $\mathrm{pH}$ and adding desired amount of adsorbent the mixture was agitated on mechanical shaker for $30 \mathrm{~min}$ at $25^{\circ} \mathrm{C}$. After that the mixture was filtered to separate the adsorbent from supernatant. The residual concentration of lead in supernatant was determined by flame atomic spectrometer. All experiments were replicated thrice for all the adsorbents and results were averaged. The removal percentage $(R \%)$ of lead was calculated for each run by following expression:

$$
\mathrm{R} \%=\frac{\left(C_{i}-C_{e}\right)}{C_{i}} \times 100
$$

where $C_{\mathrm{i}}$ and $C_{\mathrm{e}}$ were the initial and final concentration of lead in the solution. The adsorption capacity of an adsorbent which is obtained from the mass balance on the sorbate in a system with solution volume $V$ is often used to acquire the experimental adsorption isotherms. Under the experimental conditions, the adsorption capacities of all the adsorbents for each concentration of lead(II) ions at equilibrium were calculated using Eq. (2). 


$$
\mathrm{q}_{\mathrm{e}}(\mathrm{mg} / \mathrm{g}) \%=\frac{\left(C_{i}-C_{e}\right)}{M} \times V
$$

where $C_{\mathrm{i}}$ and $C_{\mathrm{e}}$ were the initial and final concentration of lead in the solution respectively $\left(\mathrm{mg} \mathrm{L}^{-1}\right) . V$ is the volume of solution (L) and $M$ is the mass of adsorbent (in g) used.

\section{RESULTS AND DISCUSSION}

\section{Adsorbent characterization}

Scanning electronic microscope is widely used to study the morphological features of the adsorbent. An observation of the SEM micrographs of nettle ash (Fig. 1) indicates the presence of many pores and a rough structure on the surface of NA, which is favorable for adsorption.

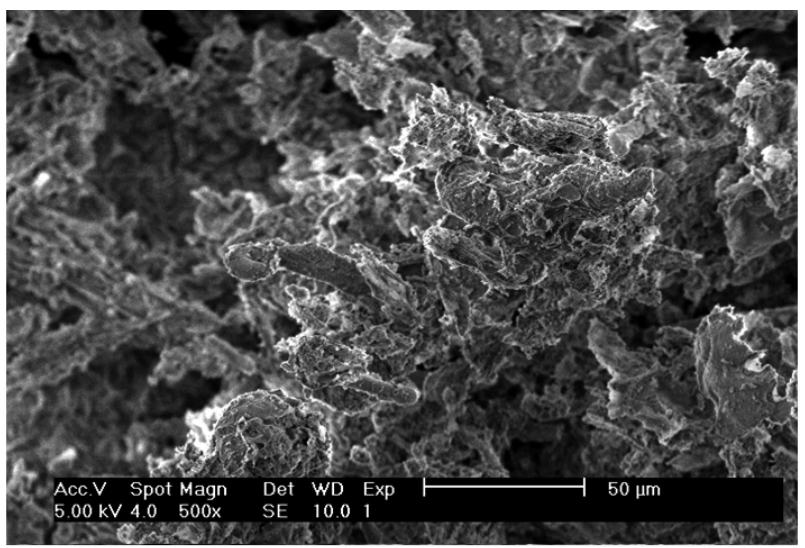

Figure 1. Scanning electron micrograph of NA.

\section{Effect of $\mathrm{pH}$}

The $\mathrm{pH}$ of the solution has a significant impact on the uptake of heavy metals, since it determines the surface charge of the adsorbent, the degree of ionization and speciation of adsorbate. ${ }^{29,30}$ In order to establish the effect of $\mathrm{pH}$ on the sorption of lead (II), the batch equilibrium studies at different $\mathrm{pH}$ values was carried out in the range of 2-8.

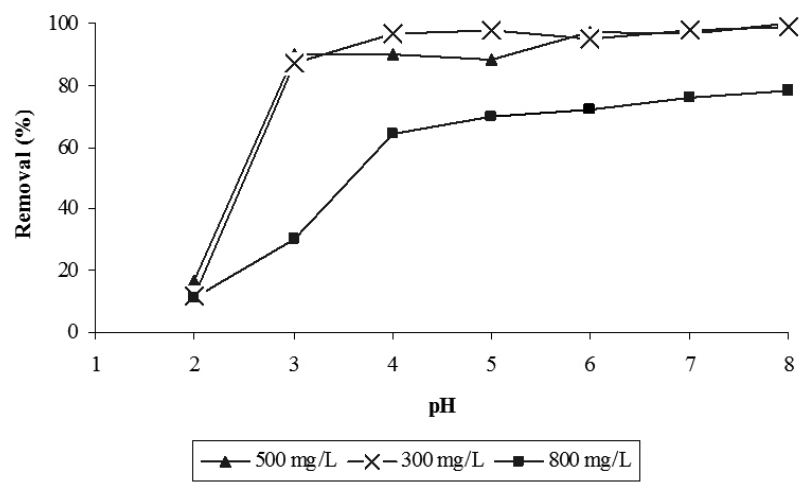

Figure 2. Effect of $\mathrm{pH}$ on adsorption of $\mathrm{Pb}$ (II) onto NA

Conditions: $2.0 \mathrm{~g} \mathrm{~L}^{-1}$ of $\mathrm{NA}, 100 \mathrm{~mL}$ of $\mathrm{Pb}(\mathrm{II})$ solution, temperature 25 ${ }^{\circ} \mathrm{C}$.

It is well known that sorption of heavy metal ions by solid substrates depends on the $\mathrm{pH}$ of the solution. Fig. 2. shows that uptake capacity and \% removal of $\mathrm{Pb}$ (II) by nettle ash decreased with increase in $\mathrm{pH}$. It is generally known that at low $\mathrm{pH}$ values, solution is strongly acidic and the surface of the sorbent is surrounded by hydrogen ions, which prevent the metal ions from approaching the binding sites on the sorbent. Due to this reason, it is thought that sorption capacity increases with increase in $\mathrm{pH}$. But it is important that during this study, minimum $\mathrm{pH}$ for solution media was 6 and a $\mathrm{pH}$ of 6 is not strongly acidic but slightly acidic. At $\mathrm{pH}$ value of 6 , metal ions can easily compete hydrogen ions and bind active sites of adsorbent. Due to this reason, sorption capacity and \% removal was high at $\mathrm{pH} 6$. At higher $\mathrm{pH}$ sorption capacity and $\%$ removal decreased and this decrease can be explained by the fact that at higher $\mathrm{pH}$, number of hydroxyl ions is more and chances of formation of metal hydroxides are also more that result in precipitation. This precipitaion caused a decrease in sorption capacity and $\%$ removal with increase in $\mathrm{pH}$.

\section{Effect of contact time}

The effect of contact time on the sorption of $\mathrm{Pb}$ (II) ions on nettle ash was investigated over time intervals from 10 up to $60 \mathrm{~min}$. Fig. 3 shows the sorption yield as a function of contact time. As seen from Fig. 3, it reached a maximum at about $30 \mathrm{~min}$, and almost remained constant up to $60 \mathrm{~min}$. Therefore in subsequent equilibrium experiments, 30 min was deemed more than sufficient to establish equilibrium and used in all subsequent measurements.

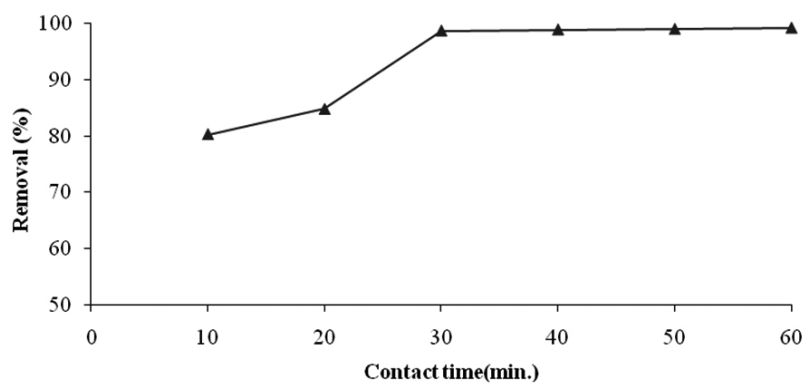

Figure 3. Effect of contact time on the removal of

Conditions: $2.0 \mathrm{~g} \mathrm{~L}^{-1}$ of NA, $100 \mathrm{~mL}$ of $200 \mathrm{mg} \mathrm{L}^{-1}$ of $\mathrm{Pb}$ (II) solution, $\mathrm{pH}=6$, temperature $25^{\circ} \mathrm{C}$.

\section{The effect of $\mathrm{NA}$ and initial $\mathrm{Pb}$ (II) concentrations}

In order to evaluate the effect of $\mathrm{Pb}$ (II) and NA concentration on the removal of this metal, the adsorption process was carried out with initial $\mathrm{Pb}$ (II) concentrations between 100 and $2500 \mathrm{mg} \mathrm{L}^{-1}$ and $\mathrm{NA}$ concentrations between 1 and $5 \mathrm{~g} \mathrm{~L}^{-1}$ at constant values of $\mathrm{pH}(6.0)$ and contact time (30 min). After reaching equilibrium, the $\mathrm{Pb}$ (II) concentration in each system was measured. The results show that the adsorption efficiency increased by increasing the $N A$ concentration even though the amount of $\mathrm{Pb}$ (II) adsorbed by per gram of $N A$ decreased, indicating that the available adsorption sites or functional groups increase with more adsorbent present, and also the interactions may occur easily between sorbent and metal ions as the amount of sorbent decreases at fixed metal ion concentration. In addition the amount of $\mathrm{Pb}$ (II) uptake increased by increasing the initial $\mathrm{Pb}$ (II) concentration, where as adsorption percentages decreases with increase in the $\mathrm{Pb}$ (II) concentration. The initial metal ion concentration plays a role as a driving force to overcome mass transfer resistance for metal ion transport between the solution and the surface of the adsorbent.

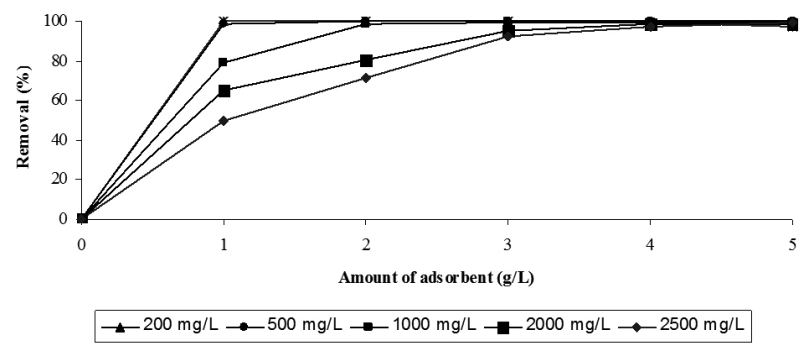

Figure 4. Effect of adsorbent dosage on the adsorption of $\mathrm{Pb}$ (II) ions Conditions: $100 \mathrm{~mL}$ of $\mathrm{Pb}$ (II) solution, $\mathrm{pH}=6$, temperature $25^{\circ} \mathrm{C}$.

The removal of lead ions was increased with increasing the NA concentrations. This is due to the greater availability of the exchangeable sites or surface area at higher concentration of the adsorbent. However by saturation of the available active sites on the surface functional groups, thus preventing further metal ion uptake. The relationship between amounts of $\mathrm{Pb}$ (II) adsorbed 
at the equilibrium $\left(\mathrm{q}_{\mathrm{e}}\right)$ and its initial concentration using different doses of NA were shown in Figure 5.

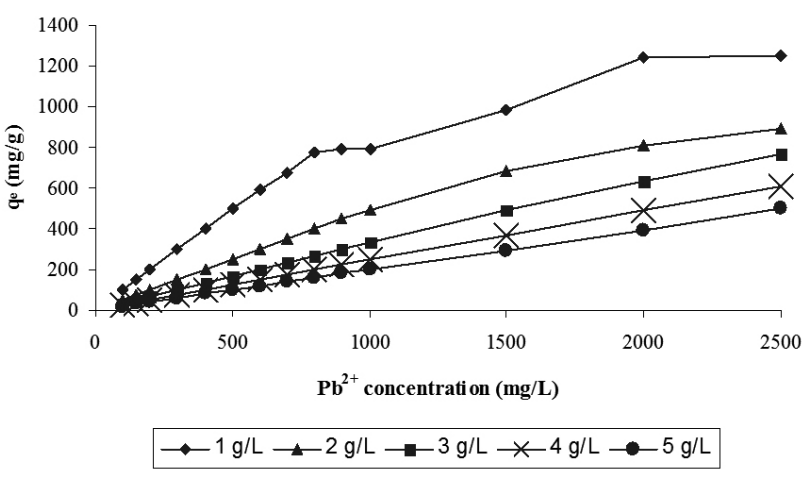

Figure 5. Relation between amounts of lead adsorbed at the equilibrium $\left(\mathrm{q}_{\mathrm{e}}\right)$ and it's initial

concentration using different doses of NA.

\section{Isotherm studies}

The sorption data obtained for variation of metal ion concentrations were treated using Langmuir, Freundlich and Temkin isotherm models as given by Equations (3) to (5). ${ }^{31}$

$$
\begin{aligned}
& \text { Langmuir equation: } \frac{c_{e}}{q_{e}}=\frac{1}{k_{L} Q_{m}}+\frac{c_{e}}{Q_{m}} \\
& \text { Freundlich equation: } \log \mathrm{q}_{\mathrm{e}}=\log \mathrm{K}_{\mathrm{F}}+\frac{1}{n} \log \mathrm{C}_{\mathrm{e}} \\
& \text { Temkin equation: } \quad \mathrm{q}_{\mathrm{e}}=\beta_{\mathrm{T}} \ln \mathrm{A}_{\mathrm{T}}+\mathrm{B}_{\mathrm{T}} \ln \mathrm{C}_{\mathrm{e}}
\end{aligned}
$$

Where $\mathrm{q}_{\mathrm{e}}$ is the amount adsorbed at equilibrium $(\mathrm{mg} / \mathrm{g})$ and $\mathrm{C}_{\mathrm{e}}$ is the equilibrium concentration of metal ions in solution $\left(\mathrm{mg} \mathrm{L}^{-1}\right)$. The other parameters are different isotherm constant, which can determine by regression of the experimental data. In the Langmuir equation, $Q_{m}(\mathrm{mg} / \mathrm{g})$ is the measure of adsorption capacity under the experimental conditions and $\mathrm{K}_{\mathrm{L}}$ is a constant related to the energy of adsorption $(\mathrm{L} / \mathrm{mg})$. Freundlich treatment gives the parameters, $\mathrm{n}$, indicative of bond energies between metal ion and the adsorbent and $\mathrm{k}_{\mathrm{F}}(\mathrm{mg} / \mathrm{g})$ related to bond strength. Where $\beta_{\mathrm{T}}==\frac{(R T)}{b}$ and $\mathrm{A}_{\mathrm{T}}(\mathrm{L} / \mathrm{g})$ are the

Temkin constant and can be determined by a plot of $\mathrm{q}_{\mathrm{e}}$ versus $\ln \mathrm{C}_{\mathrm{e}}{ }^{32}$

The Langmuir isotherm

Eq.(3) can be linearized into four different forms in Table 1, which give different parameter estimates. ${ }^{33}$

Table 1. The four linear forms of Langmuir iso.

\begin{tabular}{lcccc}
\hline Name & Linear from & Plot & Slope & Intercept \\
\hline Langmuir-1 & $\frac{c_{e}}{q_{e}}=\frac{1}{k_{L} Q_{m}}+\frac{c_{e}}{Q_{m}}$ & $\frac{c_{e}}{q_{e}}$ versus & $\frac{1}{Q_{m}}$ & $\frac{1}{k_{L} Q_{m}}$ \\
Langmuir-2 & $\frac{1}{q_{e}}=\frac{1}{\left(k_{L} Q_{m}\right)} \frac{1}{c e}+\frac{1}{Q_{m}}$ & $\frac{1}{q_{e}}$ versus $\frac{1}{c_{e}}$ & $\frac{1}{k_{L} Q_{m}}$ & $\frac{1}{Q_{m}}$ \\
Langmuir-3 & $\mathrm{q}_{\mathrm{e}}=\mathrm{Q}_{\mathrm{m}}-\left(\frac{1}{k_{L}}\right) \frac{q_{e}}{c_{e}}$ & $\mathrm{q}_{\mathrm{e}}$ versus $\frac{q_{e}}{c_{e}}$ & $\frac{1}{k_{L}}$ & $\mathrm{Q}_{\mathrm{m}}$ \\
& & & \\
Langmuir-4 & $\frac{q_{e}}{c_{e}}=\mathrm{K}_{\mathrm{L}} \mathrm{Q}_{\mathrm{m}}-\mathrm{K}_{\mathrm{L}} \mathrm{q}_{\mathrm{e}}$ & $\frac{q_{e}}{c_{e}}$ versus $\mathrm{q}_{\mathrm{e}}$ & & \\
& & $\mathrm{K}_{\mathrm{L}}$ & $\mathrm{K}_{\mathrm{L}} \mathrm{Q}_{\mathrm{m}}$ \\
\hline
\end{tabular}

The more popular linear forms used are Langmuir-1 and Langmuir-2 and the results obtained from the four forms of Langmuir model for the adsorption of $\mathrm{Pb}$ (II) onto NA shows that the adsorption of lead ions onto NA follows the Langmuir-1 form (Fig. 6).

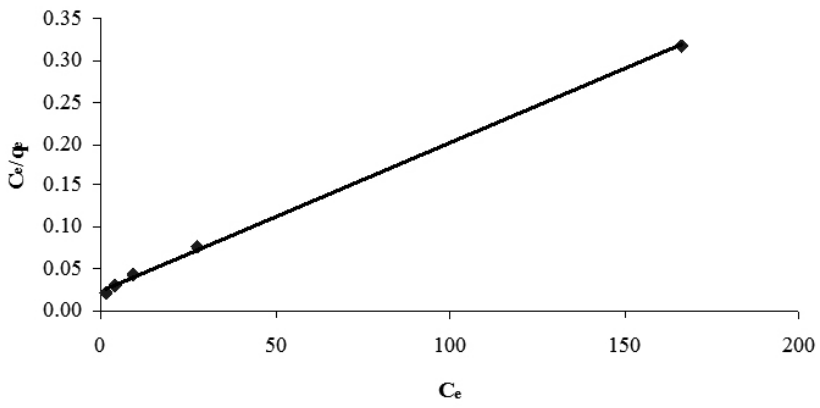

Figure 6. Langmuir-1 isotherm plot for adsorption of lead onto NA.

The maximum monolayer capacity, $\mathrm{Q}_{m}$, obtained from the Langmuir isotherm was $1000 \mathrm{mg} / \mathrm{g}$, which is higher than that obtained from previous reported studies. ${ }^{34,35}$ The essential characteristic of the Langmuir isotherm may be expressed in terms of dimensionless separation parameter $\mathrm{R}_{\mathrm{L}}$, which is indicative of the isotherm shape that predicts whether an adsorption system is favorable or unfavorable. $\mathrm{R}_{\mathrm{L}}$ is defined as:

$$
\mathrm{R}_{\mathrm{L}}=\frac{1}{1+k_{L} c_{0}}
$$

Where $K_{L}$ is the Langmuir constant. Values of $R_{L}$ are shown in Table 3. The $R_{L}$ Values for the present experimental data fall between zero and one, which is an indication of the favorable adsorption of lead on the adsorbent.

Table 2. Different values of $R_{L}$ for the adsorbent at different concentration of lead.

\begin{tabular}{|c|c|}
\hline $\mathrm{Pb}(\mathrm{II})$ Concentration $\left(\mathrm{mg} \mathrm{L}^{-1}\right)$ & $\mathrm{R}_{\mathrm{L}}$ Value \\
\hline 200 & 0.10 \\
\hline 400 & 0.054 \\
\hline 600 & 0.037 \\
\hline 800 & 0.028 \\
\hline 1000 & 0.023 \\
\hline
\end{tabular}

\section{The Freundlich isotherm}

The Freundlich equilibrium isotherm equation was also used to describe experimental adsorption data. This isotherm is an empirical equation which is used for the description of multilayer adsorption with interaction between adsorbed molecules. The model applies to adsorption onto heterogeneous surfaces with a uniform energy distribution and reversible adsorption. The Freundlich isotherm is the earliest known relationship describing the adsorption equation. The application of the Freundlich equation suggests that adsorption energy exponentially decreases on completion of the adsorptional centres of an adsorbent.

\section{The Tempkin model}

Tempkin considered the effects of some indirect adsorbate/adsorbate interactions on adsorption isotherms. They suggested that, because of these interactions and ignoring very low and very large values of concentration, the heat of adsorption of all molecules in the layer would decrease linearly with coverage.

Examination of the linear isotherm plots suggested that the Langmuir model yielded a much better fit than the other models. In addition, the approach of the isotherm parameters determination by linear regression appears to give acceptable fits to the experimental data with good respective regression coefficients ( $R^{2}$ values) as shown in the linear transform columns in Tables 3.

Table 3. Isotherm parameters obtained form the three isotherm models for the adsorption of lead onto NA.

\begin{tabular}{|c|c|c|c|c|c|c|c|c|}
\hline \multicolumn{3}{|c|}{ Freundlich isotherm } & \multicolumn{3}{c|}{ Langmuir isotherm } & \multicolumn{3}{c|}{ Temkin isotherm } \\
\hline $\mathrm{K}_{\mathrm{F}}$ & $\mathrm{n}$ & $\mathrm{R}^{2}$ & $Q_{\mathrm{m}}$ & $\mathrm{K}_{\mathrm{L}}$ & $\mathrm{R}^{2}$ & $\mathrm{~A}_{\mathrm{T}}$ & $\beta_{\mathrm{T}}$ & $\mathrm{R}^{2}$ \\
\hline 73.62 & 2.38 & 0.945 & 1000 & 0.065 & 0.999 & 1.1 & 100.5 & 0.98 \\
\hline
\end{tabular}




\section{Kinetics study}

The kinetics of $\mathrm{Pb}$ (II) adsorption was studied from the time versus \%removal curves. The rate kinetics of $\mathrm{Pb}$ (II) adsorption on the adsorbents was analyzed using the 1st-order and second order kinetic models.

The first order rate equation of Lagergren ${ }^{36}$ is one of the most widely used for the sorption of a solute from liquid solution and is represented as:

$$
\log \left(q_{e}-q_{t}\right)=\log \mathrm{q}_{\mathrm{e}}-\frac{k_{1}}{2.303} \mathrm{t}
$$

Where $\mathrm{q}_{\mathrm{e}}$ is the mass of metal of adsorbed at equilibrium $(\mathrm{mg} / \mathrm{g}), \mathrm{q}_{\mathrm{t}}$ is the mass of metal adsorbed at time $\mathrm{t}(\mathrm{mg} / \mathrm{g}), \mathrm{K}_{1}$ is the 1 st-order reaction rate constant $\left(\mathrm{min}^{-1}\right)$.

The 1st-order considers the rate of occupation of adsorption sites to be proportional to the number of unoccupied sites. It was observed that the $q$ e values estimated by 1st-order kinetic model differ substantially from those measured experimentally, suggesting that the adsorption not a first order reaction.

A second-order equation ${ }^{37}$ based on adsorption equilibrium capacity may be expressed in the form:

$$
\frac{t}{q_{t}}=\frac{1}{k_{2} q_{e}^{2}}+\frac{t}{q_{e}}
$$

Where $\mathrm{K}_{2}$ is the second-order reaction rate equilibrium constant ( $\mathrm{g} \mathrm{mg}$ $\left.{ }^{1} \mathrm{~min}^{-1}\right)$. A plot of $\frac{t}{q}$ against $\mathrm{t}$ should give a linear relationship for the $q_{t}$

applicability of the second-order kinetic. The second-order model is shown in Figure 7. The estimated model and the related statistic parameters are reported in Table 4.

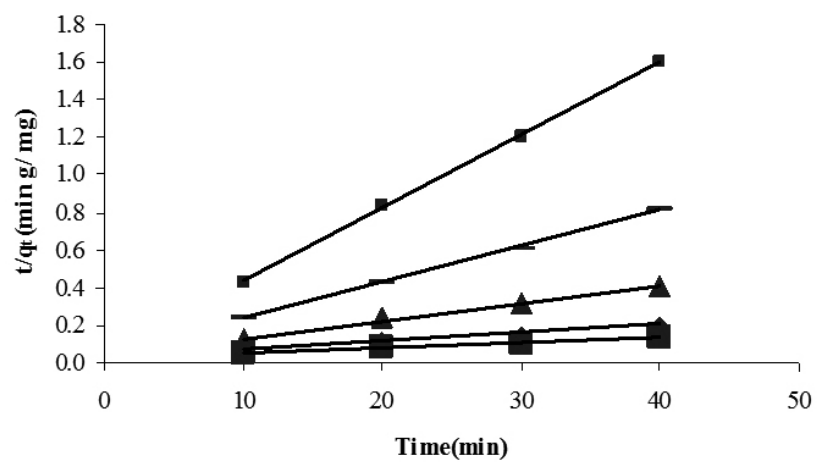

- $50 \mathrm{mg} / \mathrm{L}-100 \mathrm{mg} / \mathrm{L} \mathbf{\Delta} 200 \mathrm{mg} / \mathrm{L} \bullet 400 \mathrm{mg} / \mathrm{L}$ @ $600 \mathrm{mg} / \mathrm{L}$

Figure 7. Plot of the second-order model at different initial $\mathrm{Pb}$ (II) concentrations and $2 \mathrm{~g} \mathrm{~L}^{-1}$ of adsorbent.

The correlation coefficients for the second-order kinetic model are nearly equal to 1 . Therefore, the kinetics of lead adsorption on to the adsorbent can be described well by second-order equation.

Table 4. Parameters of estimated kinetics models for lead.

\begin{tabular}{|c|c|c|}
\hline $\mathrm{Pb}(\mathrm{II})\left(\mathrm{mg} \mathrm{L}^{-1}\right)$ & \multicolumn{2}{|c|}{ Second-order constant } \\
\hline & $\mathrm{R}^{2}$ & $\mathrm{~K}_{2}$ \\
\hline 50 & 0.999 & 0.03 \\
\hline 100 & 0.999 & $8.2 \times 10^{-3}$ \\
\hline 200 & 0.996 & $2.25 \times 10^{-3}$ \\
\hline 400 & 0.991 & $5.9 \times 10^{-4}$ \\
\hline 600 & 0.992 & $2.0 \times 10^{-4}$ \\
\hline
\end{tabular}

In this case adsorption occurs by electrostatic attraction. The adsorption of lead (II) cations was due to the surface reaction with terminal hydroxyl groups on adsorbent and the combination of positive charges of metal cations and negative charges on adsorbent surfaces. For nettle ash, aluminosilicate is the major form and presents surface hydroxyl sites in aqueous solution. The adsorption mechanism can be described in the following equations:

$$
\mathrm{M}-\mathrm{OH}+\mathrm{Pb}^{2+} \rightarrow \mathrm{M}-\mathrm{O}-\mathrm{Pb}+\mathrm{H}^{+}
$$

Comparison of Lead (II) Removal with Different Adsorbents

A comparison of the maximum adsorption capacities of some adsorbents for the $\mathrm{Pb}$ (II) removal are given Table 5. It is evident that the sorption affinity of the nettle ash is comparable or more to the other available adsorbents.

Table 5: Adsorption capacities Qm for lead (II) ions of various adsorbents.

\begin{tabular}{|c|c|}
\hline Adsorbents & $\begin{array}{c}\text { Maximum adsorption capacity, } Q_{\mathrm{m}} \\
(\mathrm{mg} / \mathrm{g})\end{array}$ \\
\hline fly ash $^{38}$ & 37.0 \\
\hline Eichhornia activated carbon $^{39}$ & 16.6 \\
\hline natural phosphate $^{40}$ & 115.0 \\
\hline sugarcane bagas $^{\text {se }} 41$ & 333.0 \\
\hline Ulmus carpinifolia $^{42}$ & 201.1 \\
\hline
\end{tabular}

We note that our material (NA) is more effective compared to other materials. However, the present experiments are conducted to find the technical applicability of the new adsorbents to treat $\mathrm{Pb}$ (II) from aqueous solutions.

\section{Desorption studies}

The reversibility of the adsorption process was also investigated. Desorption studies are helpful to explore the possibility of recovery of the metal resource. Desorption studies were carried out using $0.1 \mathrm{~mol} \mathrm{~L}^{-1} \mathrm{HCl}$ solution as stripping agents. Metal loaded adsorbent obtained from our sorption experiments was transferred to the vessels and shaken with $50 \mathrm{ml}$ of acid for 24 $\mathrm{h}$. In order to determine the reusability of the adsorbents after sorption process, the sorbents were taken out from the solution and washed with deionized water. The filtrate was analyzed for desorbed metal ion. The total loss amount of metal ion released from adsorbent varied from 5.0 to $10.0 \%$.

\section{CONCLUSIONS}

The present study indicated that the nettle ash is an effective adsorbent for the removal of $\mathrm{Pb}$ (II) from aqueous solutions. The adsorption reached equilibrium within $30 \mathrm{~min}$. The adsorption was found to be greatly dependent on solution $\mathrm{pH}$. The optimal solution $\mathrm{pH}$ range for the removal of $\mathrm{Pb}$ (II) was determined to be 6 . The maximum adsorption capacity of $\mathrm{Pb}$ (II) on NA was around $1000 \mathrm{mg} \mathrm{g}^{-1}$, which is more than other reported adsorbents. ${ }^{36-38}$ The batch adsorption data for lead was successfully correlated with Langmuir model. The kinetic sorption data fitted well to the second-order kinetic model, indicating that the intraparticle diffusion is the rate-limiting factor. Low-cost, availability and high metal uptake levels for $\mathrm{Pb}$ (II) make nettle ash a promising material for metal contaminated aqueous and wastewater treatment.

\section{ACKNOWLEDGEMENTS}

The authors thank the Research Council and office of gifted student of Semnan University for financial support.

\section{REFERENCES}

1. Calace, N.; Di, A.; Muro, E.; Nardi, M. B.; Pietroletti, M. P. Ind. Eng. Chem. Res. 2002, 41, 5491-5497.

2. Larous, S.; Meniai, A. H.; Lehocine, M. B. Desalination. 2005, 185, 483490.

3. Conrad, K.; Hansen, H. C. B. Bioresour. Technol. 2007, 98, 89-97.

4. Bailey, S. E.; Olin, T. J.; Bricka, R. M.; Adrian, D. D. Water Res. 1999, 33, 2469-2479.

5. Kortenkamp, A.; Casadevall, M.; Faux, S. P.; Jenner, A. A.; Shayer, R. O. J.; Woodbrige, N.; O'Brien, P.; Arch. Biochem. Biophys. 1996, 329, 199-208.

6. Volesky, B.; Hydrometallurgy 2001, 59, 203-216.

7. Gode, F.; Pehlivan, E. Fuel Process. Technol. 2005, 86, 875-884.

8. Atkinson, S. Membr. Technol. 2006, 3, 8-9.

9. Teker, M.; Imamoglu, M.; Saltabas, M.; Turk. J. Chem. 1999, 23, 185 192.

10. Qdais, H. A.; Moussa, H. Desalination. 2004, 164, 105-110. 
11. Rengaraj, S.; Yeon, K. H.; Kang, S. Y.; Lee, J. U.; Kim, K. W.; Moon, S. H. J. Hazard. Mater. 2002, 92, 185-198.

12. Radhika, V.; Subramanian, S.; Natarajan, K. A. Water Res. 2006, 40, 3628-3636.

13. Srivastava, S.; Ahmad, A. H.; Thakur, I. S. Bioresour. Technol. 2007, 98, $1128-1132$.

14. Mohan, D.; Singh, K. P.; Singh, V. K. Ind. Eng. Chem. Res. 2005, 44, $1027-1042$.

15. Wankasi, D.; Horsefalljnr, M.; Spiff, A. I. J. Chil. Chem. Soc. 2005, 50, 691-696.

16. Paulino, A. T.; Santos, L. B.; Nozaki, J., React. Funct. Polym. 2008, 68, 634-642.

17. Zhu, C.; Luan, Z.; Wang, Y.; Shan, X., Sep. Purif. Technol. 2007, 57, 161-169.

18. Pehlivan, E.; Yanık, B. H.; Ahmetli, G.; Pehlivan, M., Bioresour. Technol. 2008, 99, 3520-3527.

19. Pehlivan, E.; Arslan, G., Fuel Process. Technol. 2007, 88, 99-106.

20. Wong, K. K.; Lee, C. K.; Low, K. S.; Haron, M. J., Chemosphere. 2003, $50,23-28$.

21. Ajmal, M.; Rao, R. A. K.; Anwar, J. A.; Ahmad, R., Bioresour. Technol. 2003, 86, 147-149.

22. Teker, M.; Imamoglu, M.; Saltabas, O., Turk. J. Chem. 1999, 23, 185-192.

23. Stylianou, M. A.; Inglezakis, V. J.; Moustakas, K. G.; Malamis, S. Ph.; Loizidou, M. D., Desalination. 2007, 215, 133-142.

24. Asadi, F.; Shariatmadari, H.; Mirghaffari, N., J. Hazard. Mater. 2008, 154, 451-458.

25. Kaczala, F.; Marques, M.; Hogland, W., Bioresour. Technol.2009, 100, 235-243
26. King, P.; Srivinas, Kumar, Y. P.; Prasad, V.S. R. K., J. Hazard. Mater. 2006, 136, 560-566.

27. Orhan, Y.; Buyukgungor, H., Water Sci. Technol. 1993, 28, 247-255.

28. Abdel-Ghani, N. T.; Hefny, M. M.; El-Chaghaby, G. A. J. Chil. Chem. Soc.2008, 53, 1585-1587.

29. Panday, K. K.; Prasad, G.; Singh, V. N., Water Res. 1985, 19, 869-873.

30. Nomanbhay, S. M.; Palanisamy, K., J. Biotechnol. 2005, 8, 43-53.

31. Seader, J. D.; Henly, E. J. Separation Process Principles, 2nd ed., John Wiley \& Sons Inc., USA, 2006

32. Akkaya, G.; Ozer, A. Process Biochem. 2005, 40, 3559-3568.

33. Weber, T. W.; Charaborty, R. K. J. Am. Inst. Chem. Eng. 1974, 20, $228-$ 236.

34. Rao, M.; Ramana, M.; Seshaiah, M. D. K.; Wang, M. C.; Chien, S. W.C. J. Hazard. Mater. 2009, 166, 1006-1013.

35. Schiewer, S.; Patil, S. B. Bioresour. Technol. 2008, 99, 1896-1903

36. Taty-Costodes, V.C.; Fauduet, H.; Porte, C.; Delacroixs, A. J. Hazard. Mater. 2003, 105, 121-142.

37. Mc Kay, G.; Ho, Y.S. Process Biochem. 1999, 34, 451-465.

38. Wang, S.; Terdkiatburana, T.; Tade, M. O. Sep. Purif. Technol. 2008, 58, 353-358

39. Shekinah, P.; Kadirvelu, K.; Kanmani, P.; Senthilkumar, P.; Subburam, V. J. Chem. Technol. Biotechnol. 2002, 77, 458-464.

40. Mouflih, M.; Aklil, A.; Jahroud, N.; Gourai, M.; Sebt, S. Hydrometallurgy, 2006, 81, 219-225.

41. Karnitz Júnior, O.; Gurgel, L. V. A.; Pereira de Freitas, R.; Gil, L. F. Carbohydrate Polymers, 2009, 77, 643-650.

42. Sangi, M. R.; Shahmoradi, A.; Zolgharnein, J.; Azimi, G. H.; Ghorbandoost, M. J. Hazard. Mater. 2008, 155, 513-522. 